\title{
PENERAPAN PENDEKATAN PEMBELAJARAN STUDENT TEAMS ACHIEVEMENTS DIVISIONS (STAD) UNTUK MENINGKATKAN HASIL BELAJAR MATEMATIKA SISWA KELAS VI SDN 035 TARAIBANGUN KECAMATAN TAMBANG KABUPATEN KAMPAR
}

\author{
Iswati Iswati \\ SDN 035 Taraibangun \\ Iswatimw1975@gmail.com
}

\begin{abstract}
ABSTRAK
This research is motivated by the difficulty in teaching geometry caused by the learning that is not appropriate, so students' mathematics learning results are low. For that reason, there is a need to improve learning by applying the Student Team Achievement Division (STAD) learning approach. The purpose of this study is to improve the mathematical learning results of fifth-grade students of SDN 035 Taraibangun, Kampar, through the application of the STAD cooperative learning approach. This research is a classroom action research (CAR) consisting of two cycles and its implementation is in the fifth grade. The location of this research is carried out at SDN 035 Taraibangun, Kampar. Data collection has been done using test items and observation sheets. The results showed that in the initial cycle before learning using the STAD approach, student mathematics learning results were low with an average score of 58. After the implementation of the STAD approach, students' learning results in the first cycle increased with an average value of 84, and the results of observation sheets showed that students could work with their groups and know their peers. Then, in the second cycle, the students' learning results increased to 91. In addition, the results of observations showed that the students worked with their groups and were familiar with peer tutors. Therefore, the research hypothesis is accepted. It means that the application of STAD could improve mathematics learning results about the volume for the fifthgrade students at SDN 035 Taraibangun, Kampar.
\end{abstract}

Kata Kunci: Student Team Achievement Division (STAD) learning approach, mathematics learning results.

\section{PENDAHULUAN}

Matematika adalah ilmu pasti. Materi dalam pelajaran ini sebagian besar menggunakan rumus. Salah satu materinya adalah geometri. Contoh bangun ruang seperti kubus, balok, tabung dan lain-lain. Adanya kesulitan dalam mengajarkan materi volume bangun ruang khususnya volume tabung atau silinder menyebabkan rendahnya hasil belajar dalam pelajaran Matematika.

Hasil belajar Matematika dapat optimal jika seluruh komponen pembelajaran tersedia dan berfungsi secara optimal juga. Salah satu komponen keberhasilan

Iswati, Penerapan Pendekatan Pembelajaran Student Teams Achievements Divisions (STAD) Untuk Meningkatkan Hasil Belajar Matematika Siswa Kelas VI SDN 035 Taraibangun Kecamatan Tambang Kabupaten Kampar 
pembelajaran yang memiliki kontribusi tinggi adalah desain pembelajaran yang dilakukan oleh guru. Desain pembelajaran dan peran aktif siswa secara intelektual dan emosional kurang, berdampak pada hasil belajar matematika yang tidak optimal. Kondisi tersebut terjadi kelas VI dimana dua kali ulangan harian Matematika hasilnya belum baik. Oleh karena itu desain pembelajaran yang dilakukan guru harus mengacu pada pembelajaran yang inovatif.

Sebagai upaya untuk perbaikan pembelajaran dengan meningkatkan hasil belajar matematika, maka dilakukan dengan menggunakan pendekatan pembelajaran STAD yang dapat mengaktifkan siswa dalam belajar. Ibrahim: 2001; Trianto 2009:68) mengatakan Pembelajaran STAD merupakan salah satu tipe dari model pembelajaran kooperatif dengan menggunakan kelompokkelompok kecil dengan jumlah anggota tiap kelompok 4-5 orang siswa secara heterogen yang diawali dengan penyampaian tujuan pembelajaran, penyampaian materi, kegiatan kelompok, kuis, dan penghargaan kelompok.

Menurut Slavin (Rusman, 2011) model Pembelajaran STAD merupakan variasi pembelajaran kooperatif yang paling banyak diteliti. Model ini juga sangat mudah diadaptasi, telah digunakan dalam matematika pada tingkat sekolah dasar. Dengan demikian siswa akan mudah menelaah dan mengerti tentang volume bangun ruang, serta dapat menambah rasa kebersamaan pada siswa sehingga hasil belajar dapat meningkat. Hal ini perlu dilakukan karena tinggi rendahnya pencapaian hasil belajar siswa pada mata pelajaran Matematika akan mencerminkan tingkat keberhasilan dalam proses belajar mengajar.

Untuk itu, dalam upaya meningkatkan hasil belajar matematika khususnya pada materi volume tabung, maka dilakukan dengan menggunakan media pembelajaran bangun tabung dan pendekatan pembelajaran kooperatif STAD agar siswa lebih tertarik dan antusias dalam mengikuti pelajaran. Dengan pendekatan ini diharapkan siswa lebih mudah dalam menelaah dan mengerti tentang materi bangun tabung yang diajarkan. Hal ini dapat memungkinkan adanya peningkatan hasil belajar siswa.

Berdasarkan uraian di atas, hasil belajar Matematika Kelas VI SDN 035 Taraibangun Kecamatan Tambang Kabupaten Kampar masih rendah terutama

Iswati, Penerapan Pendekatan Pembelajaran Student Teams Achievements Divisions (STAD) Untuk Meningkatkan Hasil Belajar Matematika Siswa Kelas VI SDN 035 Taraibangun Kecamatan Tambang Kabupaten Kampar 
pada materi geometri, khususnya geometri bangun ruang. Oleh karena itu, peneliti melakukan penelitian dengan judul "Penerapan Pendekatan Pembelajaran STAD untuk Meningkatkan Hasil Belajar Matematika Siswa Kelas VI SDN 035 Taraibangun Kecamatan Tambang Kabupaten Kampar".

Penemuan ini mengikuti pertanyaan yang digunakan sebagai rumusan masalah penelitian yaitu apakah melalui penerapan pendekatan pembelajaran STAD dapat meningkatkan hasil belajar Matematika bagi siswa kelas VI SDN 035 Taraibangun Kecamatan Tambang Kabupaten Kampar? Selanjutnya berdasarkan rumusan masalah tersebut maka tujuan penelitian ini yaitu untuk meningkatkan hasil belajar Matematika siswa kelas VI SDN 035 Taraibangun Kecamatan Tambang Kabupaten Kampar melalui penerapan pendekatan pembelajaran kooperatif STAD.

\section{METODE PENELITIAN}

Penelitian ini merupakan Penelitian Tindakan Kelas (PTK) yang terdiri dari dua siklus yaitu siklus I dan siklus II yang setiap siklusnya terdiri dari: (1) Perencanaan (Planning), (2) Tindakan dan observasi, (3) Refleksi (Reflecting) Arikunto (Lazim N, dkk 2018; Nurmi dkk: 2018). Pelaksanaan siklus dua dilakukan untuk memperbaiki kesalahan-kesalahan yang muncul pada pembelajaran siklus I. Dalam proses pembelajarannya, siswa yang telah dijadikan sampel dibagi menjadi kelompok-kelompok kecil yang setiap kelompok terdiri dari 4-5 orang siswa secara heterogen.

Penelitian ini terdiri dari variabel bebas dan variabel terikat. Variabel bebasnya adalah STAD, sedangkan variabel terikatnya adalah hasil belajar Matematika yang berupa nilai kognitif yang berupa angka.

Pelaksaanaan penelitian ini dilakukan di SDN 035 Taraibangun Kecamatan Tambang Kabupaten Kampar dengan jumlah siswa kelas VI 51 orang yang terdiri dari dua kelas. Waktu penelitian pada tanggal 1 sampai dengan 31 Agustus 2018, semester I Tahun Pelajaran 2018/2019.

Penelitian ini menggunakan dua teknik mengumpulkan data yaitu teknik tes dan teknik non tes. Teknik tes digunakan untuk mendapatkan data primer berupa

Iswati, Penerapan Pendekatan Pembelajaran Student Teams Achievements Divisions (STAD) Untuk Meningkatkan Hasil Belajar Matematika Siswa Kelas VI SDN 035 Taraibangun Kecamatan Tambang Kabupaten Kampar 
hasil belajar Matematika melalui butir soal tes yang penyusunannya dilengkapi dengan kisi-kisi soal. Sedangkan teknik yang kedua yaitu non tes dapat diperoleh dari observasi pembelajaran menggunakan lembar observasi atau pengamatan.

Analisis data terdiri atas dua data. Data tes yang dianalisa yaitu hasil belajar Matematika tentang volume tabung dan masalah yang berkaitan dengan volume tabung. Data tes pertama yaitu data tes kuantitatif yang dianalisa dengan metode analisis deskriptif komparatif yang membandingkan data nilai awal tes dengan data siklus I dan siklus II. Sedangkan data tes yang kedua yaitu data hasil observasi yang merupakan data kualitatif yang dilakukan dengan membandingkan data hasil observasi antar siklus yang didapat dari observasi teman sejawat.

Hipotesis dalam penelitian ini yaitu melalui penerapan pembelajaran STAD dapat meningkatkan hasil belajar Matematika tentang volume bangun ruang bagi siswa kelas VI SDN 035 Taraibangun Kecamatan Tambang Kabupaten Kampar.

\section{HASIL DAN PEMBAHASAN}

Berdasarkan hasil penelitian dan analisis data yang telah dilakukan diperoleh data pada tabel 1 sebagai berikut:

Tabel 1. Perbandingan Hasil Observasi siklus I dan Siklus II

\begin{tabular}{|c|c|c|c|c|c|}
\hline \multicolumn{3}{|l|}{ Siklus I } & \multicolumn{3}{|l|}{ Siklus II } \\
\hline \multirow[t]{2}{*}{ Observasi Guru } & \multicolumn{2}{|c|}{ Jawaban } & \multirow[t]{2}{*}{ Observasi Guru } & \multicolumn{2}{|c|}{ Jawaban } \\
\hline & $\mathrm{Ya}$ & Tidak & & $\mathrm{Ya}$ & Tidak \\
\hline $\begin{array}{l}\text { 1. Guru menyampaikan } \\
\text { tujuan dan memotivasi } \\
\text { siswa }\end{array}$ & $\checkmark$ & & $\begin{array}{l}\text { 1. Guru menyampaikan } \\
\text { tujuan dan memotivasi } \\
\text { siswa }\end{array}$ & $\checkmark$ & \\
\hline $\begin{array}{l}\text { 2. Guru menyampaikan } \\
\text { informasi tentang } \\
\text { materi }\end{array}$ & $\checkmark$ & & $\begin{array}{l}\text { 2. Guru menyampaikan } \\
\text { informasi tentang } \\
\text { materi }\end{array}$ & $\checkmark$ & \\
\hline $\begin{array}{l}\text { 3. Guru membimbing } \\
\text { siswa membentuk } \\
\text { kelompok belajar }\end{array}$ & $\checkmark$ & & $\begin{array}{l}\text { 3. Guru membimbing } \\
\text { siswa membentuk } \\
\text { kelompok belajar }\end{array}$ & $\checkmark$ & \\
\hline 4. Guru membimbing & $\checkmark$ & & 4. Guru membimbing & $\checkmark$ & \\
\hline
\end{tabular}

Iswati, Penerapan Pendekatan Pembelajaran Student Teams Achievements Divisions (STAD) Untuk Meningkatkan Hasil Belajar Matematika Siswa Kelas VI SDN 035 Taraibangun Kecamatan Tambang Kabupaten Kampar 


\begin{tabular}{|l|l|l|l|l|l|}
\hline $\begin{array}{l}\text { kelompok kerja pada } \\
\text { saat mengerjakan } \\
\text { tugas }\end{array}$ & & $\begin{array}{l}\text { kelompok kerja pada } \\
\text { saat mengerjakan } \\
\text { tugas }\end{array}$ & & \\
\hline $\begin{array}{l}\text { 5. Guru melakukan } \\
\text { evaluasi hasil belajar }\end{array}$ & $\checkmark$ & $\begin{array}{l}\text { 5. Guru melakukan } \\
\text { evaluasi hasil belajar }\end{array}$ & $\checkmark$ & \\
\hline $\begin{array}{l}\text { 6. Guru memberikan } \\
\text { penghargaan hasil } \\
\text { kerja individu maupun } \\
\text { kelompok }\end{array}$ & $\checkmark$ & $\begin{array}{l}\text { 6. Guru memberikan } \\
\text { penghargaan hasil } \\
\text { kerja individu maupun } \\
\text { kelompok }\end{array}$ & $\checkmark$ & \\
\hline
\end{tabular}

Berdasarkan pada tabel 1 yaitu perbandingan hasil observasi siklus I dan siklus II terlihat bahwa pada siklus 1 guru mengajar sesuai dengan langkahlangkah STAD. Begitu juga pada siklus II, guru tetap mengajar sesuai dengan langkah-langkah STAD. Selain itu, hasil observasi pada siklus I dan siklus II menunjukkan bahwa pada siklus I siswa bekerja sama dengan kelompoknya masing-masing dan siswa juga mengenal apa yang disebut dengan teman sebaya. Pada siklus II siswa tetap melakukan bekerja sama dengan kelompoknya masing-masing dan siswa juga mengenal apa yang disebut dengan tutor sebaya.

Selanjutnya, untuk melihat peningkatan hasil belajar dari kondisi awal siklus, siklus I, dan siklus II dapat dilihat pada tabel 2 berikut ini:

Tabel. 2 Perbandingan Hasil Belajar Kondisi Awal Siklus, Siklus I, dan Siklus II

\begin{tabular}{|c|c|c|c|c|c|c|}
\hline Perbandingan & \multicolumn{2}{|c|}{ Kondisi Awal } & \multicolumn{2}{c|}{ Siklus I } & \multicolumn{2}{c|}{ Siklus II } \\
\hline Rata-rata & \multicolumn{2}{|c|}{58} & \multicolumn{2}{|c|}{84} & \multicolumn{2}{c|}{91} \\
\hline Nilai $>6,5$ & Jumlah & persentase & Jumlah & persentase & Jumlah & persentase \\
\cline { 2 - 7 } Tuntas & 2 & $10 \%$ & 20 & $90 \%$ & 20 & $90 \%$ \\
\hline Nilai $<6,5$ & Jumlah & persentase & Jumlah & persentase & Jumlah & persentase \\
\cline { 2 - 7 } Belum Tuntas & 20 & $90 \%$ & 2 & $10 \%$ & 2 & $10 \%$ \\
\hline
\end{tabular}

Berdasarkan tabel. 2 perbandingan hasil belajar kondisi awal siswa, siklus I dan siklus II diketahui bahwa pada saat kondisi awal siklus dimana guru belum menggunakan pendekatan pembelajaran STAD terlihat nilai rata-rata keseluruhan 
siswa rendah yaitu 58 dan terdapat sebesar $90 \%$ siswa hasil belajarnya belum tuntas dimana siswa mendapatkan hasil belajar < dari 6,5. Selanjutnya pada saat guru menggunakan pendekatan pembelajaran STAD, pada siklus I hasil belajar siswa meningkat. Hal tersebut diketahui dari nilai rata-rata keseluruhan siswa yaitu 84 dan siswa yang mendapat nilai < dari 6,5 hanya $10 \%$. Dalam hal ini, siswa telah dapat menentukan rumus tabung, menghitung volume tabung, menghitung tinggi dan jari-jari tabung dan menyelesaikan permasalahan dengan benar pada soal yang berkaitan dengan volume tabung.

Pada pembelajaran siklus II dimana rata-rata siswa meningkat dan lebih baik dari siklus I yaitu sebesar 91 . Pada siklus ini, siswa telah dapat menentukan frekuensi, modus, median, rata-rata, dan jumlah data yang diselesaikan. Selain siswa juga dapat menyajikan data dalam bentuk tabel dan mengubah tabel menjadi diagram garis, batang dan lingkaran. Namun, pada siklus II ini masih terdapat siswa yang mendapat nilai < dari 6,5 dan sama dengan siklus I yaitu sebanyak $10 \%$ siswa tidak tuntas dalam pembelajaran. Hal tersebut dikarenakan siswa tidak menguasai materi berhitung.

Hasil belajar merupakan suatu hasil yang diperoleh oleh peserta didik setelah menjalani dan mengalami langsung proses belajar, dan hasil belajar yang diperoleh bisa berbentuk skor atau pujian. Hal ini sesuai dengan pendapat Dimyati dan Mudjiono (2006) menyatakan bahwa hasil belajar adalah hasil yang dicapai dalam bentuk angka atau skor setelah diberikan tes hasil belajar pada setiap akhir pembelajaran.

Peningkatan hasil belajar yang diperoleh oleh siswa merupakan hasil motivasi selama proses pembelajaran. Motivasi siswa merupakan hal yang menetukan keberhasilan dalam pembelajaran. Adanya motivasi, siswa akan tergerak untuk belajar sehingga mempengaruhi hasil belajar. Hal ini sesuai dengan pendapat Djamarah (2002) yang mengemukakan bahwa hasil belajar akan meningkat jika motivasi belajar bertambah. Kemudian seorang siswa melakukan aktivitas belajar karena ada yang mendorongnya, motivasilah sebagai dasar penggerak yang mendorong aktivitas belajar mahasiswa tersebut. Adanya 
motivasi yang kuat dari mahasiswa untuk belajar maka mahasiswa akan memperoleh ilmu yang sebanyak-banyaknya.

Peningkatan hasil belajar siswa secara umum dimungkinkan karena model pembelajaran yang digunakan pembelajaran STAD sehingga pembelajaran menjadi aktif yang mana berpusat pada siswa dengan menyajikan suatu permasalahan, kemudian siswa diminta untuk melaksanakan suatu percobaan sederhana berdasarkan konsep dan prinsip yang dipelajarinya. Hal ini sesuai dengan pendapat Rousseau (Sardiman, 2011) bahwa pembelajaran akan berjalan efektif bila peserta didik berperan aktif dan harus diperoleh dengan merumuskan masalah dan memecahkan masalah. Dalam pembelajaran ini guru bertindak sebagai fasilitator, bukan sebagai pemberi informasi, mahasiswa yang aktif membangun konsep-konsep yang baru melalui masalah yang harus diselesaikan melalui kegiatan percobaan sederhana tersebut

Dari analisis data secara keseluruhan menunjukkan bahwa semua prosedur pembelajaran STAD dilakukan dengan baik dan menunjukkan bahwa pendekatan pembelajaran dengan menggunakan STAD membuktikan adanya perubahan hasil belajar siswa dari awal hingga akhir dimana hasil belajar siswa tersebut meningkat.

\section{SIMPULAN}

Berdasarkan hasil olahan data dan analisis data maka diperoleh kesimpulan bahwa penerapan pendekatan pembelajaran Student Teams Achievement Division (STAD) dapat meningkatkan hasil belajar Matematika bagi kelas VI SDN 035 Taraibangun Kecamatan Tambang Kabupaten Kampar.

Hal ini ditunjukkan dari pengamatan hasil belajar dan siswa yang tuntas dalam pembelajaran Matematika pada kondisi rata-rata nilai 58 meningkat menjadi 84 pada siklus I, meningkat menjadi 91 pada siklus II jumlah siswa yang tuntas pada kondisi awal $10 \%$ menjadi $90 \%$ pada siklus I dan $90 \%$ pada siklus II. Nilai tuntas pada siklus I dan siklus II sama yaitu $90 \%$ karena faktor siswa yaitu $10 \%=$ 2 siswa tidak menguasai materi berhitung. 
Adapun saran yang diberikan dari adanya penelitian ini yaitu bagi siswa sebaiknya siswa harus dapat memacu dan memotivasi minat dirinya, meningkatkan perhatian dalam proses pembelajaran, menerima pengalaman baru melalui tutor sebaya dan meningkatkan hasil belajarnya. Bagi guru sebaiknya guru harus mengajarkan materi bangun ruang dengan mudah melalui teori atau metode baru yang digunakan sehingga dapat meningkatkan prestasi siswa. Adapun bagi sekolah yaitu sekolah harus menambah referensi PTK di sekolah agar dapat menjadi referensi sehingga mempermudahkan guru mengelola pembelajaran.

\section{DAFTAR PUSTAKA}

Arikunto, dkk. 2006. Penelitian Tindakan Kelas. Jakarta: Rineka Cipta. Djamarah, S.B. (2002). Psikologi Belajar. Jakarta: Rineka Cipta.

Dimyati dan Mudjiono. (2006). Belajar dan Pembelajaran. Jakarta: Rineka Cipta. Ibrahim, dkk. 2001. Pembelajaran Kooperatif. Surabaya: Unesa

Lazim, N. dkk. 2018. Utilizing Cooperative Learning Model Types Make a Match to Promote Primary Students' Achivement in Science. Vol.1 No. 1, hlm11-19. Nurmi. dkk. 2018. Enhancing Primary Students' Science Learning Outcome Utilizing Visual Multimedia. Vol.1 No. 2, hlm 109-115.

Rusman.2010. Model- Model Pembelajaran. Bandung: PT Raja Grafindo Persada. Jakarta 